\title{
Relações entre os jogos de papéis e o desenvolvimento psíquico de crianças de 5-6 anos*
}

\author{
Maria Lidia Sica Szymanski' (D) \\ Lisiane Gruhn Colussill (D)
}

\section{RESUMO}

Reflete-se sobre a relação entre os jogos de papéis e o desenvolvimento psíquico de crianças entre 5 e 6 anos, na perspectiva da psicologia histórico-cultural. Apresentam-se, como exemplos, excertos de jogos de papéis, selecionados entre os observados e filmados durante seis sessões de 45 minutos cada, envolvendo 12 crianças da educação infantil. Os resultados possibilitam inferências sobre suas vivências e o contexto em que interagem. Ao mesmo tempo, os jogos de papeis ampliam os processos funcionais superiores, na medida em que possibilitam às crianças uma transição entre ações com objetos concretos e ações com significados. Destaca-se que as vivências infantis manifestas nos jogos denunciam as graves questões sociais atuais. Assim, é importante que o professor reconheça e favoreça o potencial educativo dos jogos de papéis, porém para além do espaço em sala de aula, são necessárias políticas públicas que possibilitem enfrentar o desafio de educar a criança contemporânea.

\section{PALAVRAS-CHAVE}

funções psicológicas superiores; desenvolvimento infantil; psicologia histórico-cultural.

\footnotetext{
*Este trabalho é uma versão ampliada de comunicação oral apresentada na 38 Reunião Nacional da Associação Nacional de Pós-Graduação e Pesquisa em Educação (ANPEd). O texto traz um recorte dos dados já tratados em dissertação de mestrado (Colussi, 2016). 'Universidade Estadual do Oeste do Paraná, Cascavel, PR, Brasil.

"Secretaria da Educação do Estado do Paraná, Capanema, PR, Brasil.
} 


\title{
RELATIONSHIPS BETWEEN ROLE-PLAYS AND THE PSYCHIC DEVELOPMENT OF CHILDREN AGED 5-6 YEARS
}

\begin{abstract}
This study reflects on the relationship between role-plays and the psychic development of children aged 5 to 6 years from the perspective of cultural-historical psychology. As an example, we present excerpts of role-playing games, selected from the ones observed and filmed during six sessions of 45 minutes each, involving 12 children in preschool. The results allow inferences about their experiences and the context in which they live. At the same time, role-plays expand higher psychological processes, as they enable children to transition between actions with concrete objects and actions with meaning. We emphasize that the child experiences manifested in the games denounce serious social issues faced by educators today. Thus, the teacher must recognize and favor the educational potential of role-playing; however, the challenge of educating the contemporary child requires public policies beyond the classroom environment.
\end{abstract}

\section{KEYWORDS}

higher psychological processes; child development; cultural-historical psychology.

\section{RELACIONES ENTRE LOS JUEGOS DE PAPELES Y EL DESARROLLO PSÍQUICO DE NIÑOS DE 5-6 AÑOS}

\section{RESUMEN}

Se reflexiona sobre la relación entre los juegos de roles y el desarrollo psíquico de niños de 5 a 6 años, en la perspectiva de la psicología histórico-cultural. Se presentan, como ejemplos, extractos de juegos de papeles, seleccionados entre los observados y filmados durante seis sesiones de 45 minutos, involucrando a 12 niños de educación infantil. Los resultados posibilitam inferencias sobre sus subjetividades y sobre el contexto en que viven. Al mismo tiempo, los juegos de papeles amplían los procesos funcionales superiores, en la medida en que posibilitan a los niños una transición entre acciones con objetos concretos y acciones con significados. Se destaca que las vivencias infantiles manifestadas en los juegos denuncian las graves cuestiones sociales actuales. Así, es importante que el profesor reconozca y favorezca el potencial educativo de los juegos de papeles, pero más allá del espacio en el aula, son necesarias políticas públicas que posibiliten enfrentar el desafío de educar al niño contemporáneo.

funciones psicológicas superiores; desarrollo infantil; psicología histórico-cultural. 


\section{INTRODUÇÃO}

Este artigo fundamenta-se na psicologia histórico-cultural, que compreende o desenvolvimento infantil como um processo dialético de apropriações e objetivações que se expressam nas relações sociais. Sobre a base biológica constituída pelo organismo, as experiências vividas ao serem apropriadas interferem e redimensionam possibilidades, interesses e necessidades típicas de cada criança, a qual apresenta, por isso mesmo, modos próprios de atuação nas relações que a envolvem.

Nessa direção, considera-se que o desenvolvimento psicológico inicia-se à medida que a criança apodera-se dos modos de fazer e dizer, construídos coletivamente pela humanidade. Não se trata apenas de um processo de crescimento, mas sim de novas sínteses, que envolvem reorganizações psíquicas, nas quais se fundem a dimensão cultural à biológica, ainda que um aspecto não possa ser reduzido ao outro. Não há linearidade. Processos anteriores articulam-se a posteriores, numa relação dialética de transformação e mudança, uma vez que essa criança situa-se em uma realidade que envolve conhecimentos científicos, técnicos e artísticos que foram sendo construídos historicamente pela humanidade, à medida que os homens necessitavam de trabalhar para satisfazer suas necessidades biológicas e sobreviver.

Os estudos de Vigotski acerca da historicidade do psiquismo humano revelam que as características biológicas próprias da espécie exigem que o homem trabalhe para sobreviver. O trabalho coletivo demanda e propicia o avanço tecnológico, científico e cultural, favorecendo ao indivíduo a apropriação da cultura por meio da interiorização dos signos, possibilitando-lhe o desenvolvimento das funções psicológicas, isto é, das formas psíquicas que lhe permitem funcionar socialmente.

Com o desenvolvimento histórico, cultural e tecnológico humano, as necessidades biológicas, ainda que vitais, quando garantidas se tornam secundárias, e o homem privilegia as complexas necessidades sociais, que motivam a atividade humana e propiciam o surgimento e o desenvolvimento da consciência. Elas estão originalmente submetidas a relações sociais e condicionam a gênese da imagem psíquica, possibilitando às estruturas neuronais tornarem-se cada vez mais complexas (Leontiev, 1978; Luria, 1991).

Destaca-se, portanto, que a consciência não resulta unicamente do mundo subjetivo, nem tampouco é resultado de um processo apenas biológico, uma vez que ela se forma nas relações do sujeito com o mundo à sua volta. Trata-se de um movimento dialético, no qual, ao mesmo tempo em que a consciência vai ampliando-se, amplia-se a representação interna do mundo externo - apropriação que depende da atividade do sujeito. Essa consciência regula a forma como o sujeito realiza a própria atividade.

Tal processo constante ocorre em consequência da participação do sujeito em atividades compartilhadas, possibilitando, a partir do entrecruzamento orgânico e cultural, desenvolverem-se suas funções psíquicas superiores. Essas funções consistem em ações conscientes e controladas, como pensamento abstrato, raciocínio, atenção voluntária, percepção, sentimentos, memória mediada, linguagem, vontade, entre outras.

E importante ressaltar que, antes de se constituírem como psicológicas, essas funções tipicamente humanas perpassam pelas relações entre as pessoas, em um processo interpessoal que se transforma em intrapessoal. Assim, a visão biologizante que entendia esse processo como a-histórico e natural revela-se frágil, e 
o conceito de signo que - análogo ao conceito de instrumento, o qual medeia a relação material entre o homem e o mundo - atua como mediador psíquico nessa relação torna-se fundamental.

Portanto, funções psíquicas superiores nada mais são do que o resultado de um processo contínuo de transformação das funções biológicas a partir da apropriação dos sistemas de signos. A apropriação e a utilização de signos possibilita aos processos funcionais ultrapassarem os limites do sistema orgânico de atividades, e, consequentemente, os comportamentos podem tornar-se conscientemente planejados e controlados. Nesse sentido, função é compreendida como ação que "[...] principia externamente" (Martins, 2013, p. 98), uma vez que essas mudanças no desenvolvimento psíquico ocorrem por meio das atividades que a criança desempenha em seu cotidiano.

\section{O CONCEITO DE ATIVIDADE}

Entende-se como atividade "[...] o modo/meio pelo qual a criança estabelece relações com a realidade externa tendo em vista a satisfação de suas necessidades" (Martins, 2006, p. 30). Entre essas atividades, destaca-se a atividade principal ou atividade-guia, ou seja, aquela que promove "as mais importantes mudanças no desenvolvimento psíquico da criança e dentro da qual se desenvolvem processos psíquicos que preparam o caminho da transição da criança para um novo e mais elevado nível de desenvolvimento" (Leontiev, 2016, p. 122).

Elkonin (1987), embasado nos estudos de Vigotski e apreendendo a categoria da atividade em Leontiev, investigou qual a atividade-guia e suas características, bem como as forças motrizes que possibilitam a passagem entre os períodos que compõem o desenvolvimento psíquico: primeira infância, infância e adolescência. Cada período se subdivide em dois grupos: um relativo à esfera motivacional e das necessidades, e o outro à esfera das possibilidades técnicas e operacionais. A seguir, são destacados os principais aspectos dos dois primeiros, os quais se relacionam com o objeto do presente estudo:

1. No período da primeira infância - que vai desde o nascimento até aproximadamente um ano e envolve os estágios de comunicação emocional direta -, a comunicação do bebê com os adultos é a atividade principal. Nesse período, o contato da criança com o mundo é socialmente mediado e dependente. Desenvolvem-se suas possibilidades de manipulação dos objetos que fazem parte de sua realidade. Ainda, na relação afetiva e motora com os que dela cuidam, a criança inicia o processo de assimilação das tarefas, dos motivos e das normas da atividade humana e de relacionamento entre as pessoas.

Iniciam-se, assim, suas primeiras possibilidades técnicas e operacionais de manipulação objetal e, por meio da linguagem e da demonstração do adulto, a criança apropria-se dos procedimentos socialmente elaborados de ação sobre os objetos. “Assim, a comunicação direta 'criança-adulto', cede [gradativamente] lugar à comunicação indireta "criança-ações com objeto-adulto"' (Elkonin, 2009, p. 215). 
2. O segundo período denomina-se infância e compreende a atividade-guia jogo de papéis (1 $1^{\circ}$ grupo), aproximadamente dos 3 aos 6 anos, e a atividade-guia estudo ( $2^{\circ}$ grupo), aproximadamente dos 6 anos ao início da adolescência. Nesse período, pela mediação social, amplia-se o desenvolvimento da linguagem e o sistema de signos utilizados pela criança. Ao utilizar os jogos de papéis, a criança toma posse do mundo concreto dos objetos humanos, quando reproduz as ações realizadas pelos adultos com esses objetos.

Pouco a pouco, a criança, ao adentrar no ensino fundamental, passa a ter como atividade-guia o estudo. "Na escola, a criança tem deveres a cumprir, tarefas a executar e, pela primeira vez em seu desenvolvimento, tem a impressão de estar realizando atividades verdadeiramente importantes" (Facci, 2004, p. 70). O relacionamento da criança com os adultos que a cercam tem o estudo como intermediário, ou seja, ocorrem mudanças em relação à sua comunicação pessoal com a família e organização da rotina diária. A assimilação de novos conhecimentos ocorre durante essa atividade-guia, e o ensino escolar deve direcionar a criança para essa atividade de estudo (Elkonin, 2009).

Entre esses períodos, tendo em vista os objetivos propostos no presente estudo, esta pesquisa volta seu foco ao segundo período - a infância -, nela destacando sua atividade-guia, ou seja, o jogo de papéis. ${ }^{1}$ Para discutir esse conceito e a contribuição dos jogos de papéis na constituição do desenvolvimento psíquico, desenvolveu-se uma pesquisa de campo, relatada a seguir.

\section{METODOLOGIA}

Com base no referencial apresentado, a pesquisa de campo envolveu crianças na faixa etária de 5 a 6 anos, frequentando uma turma da educação infantil, com o objetivo de verificar como os jogos de papéis se manifestam nas brincadeiras infantis. $\mathrm{Na}$ análise dos papéis protagonizados e da fala infantil, revelam-se pensamentos desconhecidos, necessidades e representações trazidas pelas crianças. Assim, objetivou-se apreender os sentidos dessas representações, mediante uma reflexão dialética entre os pressupostos teóricos e os dados empíricos, na busca de superá-los, indo além do que as aparências revelam, a fim de compreender o sujeito.

Os dados foram gerados em uma instituição pública de ensino, que fora sugerida em contato prévio com a Secretaria Municipal de Educação, pela disponibilidade para a pesquisa e por apresentar características comuns a qualquer escola do município, uma vez que a parte contém as propriedades do todo e "o processo apreendido [...] pode revelar algo constitutivo de [...] [outras instituições] que vivem em condições semelhantes" (Aguiar, 2001, p. 140).

As observações foram realizadas na única turma de pré-escolar funcionando à tarde, envolvendo a professora titular e 12 crianças, 2 com 5 anos e 10 com 6 anos, sendo 6 meninas e 6 meninos.

1 Neste trabalho, baseado em Elkonin (2009), as expressões “jogos de papéis”, "brincadeira de papéis" e "jogos protagonizados" são entendidas como sinônimos. 
$\mathrm{Na}$ fase I da pesquisa, com seis horas de observação distribuídas em três dias, constatou-se que cada criança limitava-se a levar um brinquedo na sexta-feira, no último horário para participar do "Dia do Brinquedo", assim intitulado pela instituição. Essa limitação de tempo e espaço refletia-se no brincar, cerceando a evolução para jogos de papéis.

Tendo em vista o objetivo desta pesquisa, para o desenvolvimento da fase II organizou-se um espaço físico com brinquedos e readequou-se o horário das atividades pedagógicas, prevendo um tempo livre maior para que a brincadeira de papéis emergisse. Nessa fase, utilizou-se o espaço da biblioteca para organização dos materiais lúdicos (bonecas, brinquedo relativos às profissões de médico, professora, mecânico, cabeleireiro, carrinhos, utensílios e móveis de cozinha, cabaninha etc.), uma vez que um arranjo adequado favoreceria a interação entre as crianças.

O fundamental é compreender que essas possibilidades de aprendizagem são resultado de processos espontâneos, mas requerem alguns elementos mediadores (internos e externos). Mediadores internos são, por exemplo, as memórias de situações, as percepções e sensações, as expectativas e necessidades das crianças, que vão se apresentando ao longo da experiência cotidiana. [...] um mediador externo à criança importante são os brinquedos e artefatos (objetos, indumentárias, etc.) e, em especial, a presença de outras crianças [...]. (Oliveira, 2011, p. 143)

As filmagens, na fase II, durante um período de quinze dias, envolveram seis sessões, com 45 minutos cada, totalizando $4 \mathrm{~h} 30 \mathrm{~min}$, posteriormente transcritas para análise. Embora se tenha alterado o horário escolar e inserido artificialmente um espaço para brincadeira de papéis, pode-se considerar que a artificialidade refere-se à dinâmica escolar, e não ao desempenho das crianças durante o jogo de papéis.

Durante as sessões, as gravações eram descontínuas porque foram registrados os momentos e as brincadeiras em que os jogos de papéis apareceram. Procurou-se registrá-los desde o início (ou pelo menos quando a pesquisadora os identificava) até o seu término, o que ocorria em virtude de vários aspectos, tais como: interferência de outra criança, mudança de tema na brincadeira, mudança de área de trabalho ou de brinquedo.

Utilizaram-se duas câmeras e duas pessoas para a filmagem, o que permitiu registrar mais episódios e perceber detalhes. Durante as gravações, procurou-se interferir o menos possível nas interações entre as crianças, apenas o fazendo quando solicitado, o que raramente ocorreu. $\mathrm{Na}$ transcrição, identificaram-se as falas das crianças com a letra inicial do primeiro nome e, quando necessário, do segundo nome. Denominou-se P1 a professora da turma e P2 a observadora.

\section{O CAMINHO DA ANÁLISE}

Para compreender o constante movimento de construção do psiquismo, foi necessário identificar o que o move, ou seja, o emprego de signos. Os signos utilizados possibilitam a análise de seu significado social e do sentido pessoal, permitem ir além do aparente e pensar em processos, objetos ou situações até então 
não revelados. Os signos apropriados pelo sujeito foram primeiramente externos, para então se tornarem internos e se constituírem em instrumentos para o processo de mediação que tanto possibilitou a própria apropriação dos signos, tal como se objetivou no momento da brincadeira, possibilitando novas apreensões do social.

$\mathrm{Na}$ análise dos resultados, os processos funcionais não foram considerados separadamente nos episódios, pois "as transformações específicas de cada função determinam modificações no conjunto de funções do qual fazem parte, isto é, do psiquismo como um todo" (Martins, 2013, p. 70).

Da mesma forma que a utilização de uma ou outra ferramenta determina todo o mecanismo da operação de trabalho, assim também a natureza do signo utilizado constitui o fator fundamental do qual depende a construção de todo o processo [de desenvolvimento das funções psicológicas superiores]. A relação mais essencial que subjaz na estrutura superior é a forma especial de organização de todo o processo, que se constrói graças à introdução na situação de determinados estímulos artificiais que cumprem o papel de signos. (Vygotsky, 1995, p. 123, tradução nossa)

Desse modo, compreender as palavras/signos foi o ponto de partida para as análises dos dados. Porém, "para compreender a fala de alguém, [...] é preciso compreender seu pensamento (que é sempre emocionado), é preciso apreender o significado da fala. O significado é [...] a unidade do pensamento e da linguagem" (Aguiar, 2001, p. 130).

\section{OS PROCESSOS FUNCIONAIS E OS JOGOS DE PAPÉIS}

Utiliza-se o termo "jogo de papéis" 2 para designar a brincadeira de faz de conta não estruturada, com regras subentendidas e papéis definidos, por meio dos quais as crianças reproduzem os papéis sociais adultos com o intuito de inserção na sociedade (Elkonin, 1987). Na medida em que, historicamente, as relações sociais do adulto e da criança diversificaram-se, o jogo de papéis surgiu como necessidade psicológica. Portanto, sua origem relaciona-se "com condições sociais muito concretas da vida da criança na sociedade e não com a ação de energia instintiva inata [...]" (Elkonin, 2009, p. 80).

Por isso a brincadeira de jogos protagonizados não se configura como espontânea, mas como produção infantil que se baseia nas relações estabelecidas entre os adultos e entre os adultos e as crianças (Elkonin, 2009). A principal característica da atividade lúdica no jogo de papéis é o fato de a criança elaborar uma situação fictícia para representar um papel de adulto, conforme o sentido que ela lhe atribui, transferindo as significações de um objeto a outro.

2 Assim como Couto (2013), apoiar-nos-emos em Lazaretti (2008) e adotaremos a expressão "jogo de papéis”, por corresponder à tradução do russo Rolevoii Igri para o espanhol, e deste para o português, tradução que será utilizada neste trabalho. Em citações diretas será mantido o termo original apresentado na obra. Vigotski (Vigotsky, 2008) utiliza o termo "brincadeira" com o mesmo sentido. 
Para compreender o sentido das brincadeiras de papéis protagonizadas pelas crianças, inicialmente foram buscados seus temas centrais, que foram então organizados e transcritos em 23 episódios. Para os recortes no filme, foram utilizados como critério o aparecimento do jogo de papéis no ato da brincadeira e a qualidade do registro, isto é, se havia a possibilidade de compreensão das falas das crianças, uma vez que, em virtude da algazarra infantil e do pequeno alcance do microfone, algumas falas ficaram inaudíveis. $\mathrm{O}$ Quadro 1 apresenta os episódios trazidos pelas crianças em suas brincadeiras de papéis.

Quadro 1 - Episódios de jogos de papéis de crianças de 5-6 anos: argumento e título da brincadeira de papéis.

\begin{tabular}{|l|c|}
\hline Argumento no jogo de papéis (Tema) & Título da brincadeira de papéis \\
\hline Casinha I & Que seja de menina... \\
\hline Casinha II & Pipoca de melado \\
\hline Casinha III & A mãe quer \\
\hline Casinha IV & Vinho ou suco? \\
\hline Casinha V & Brincando no tobogã \\
\hline Casinha VI & Mãe trabalhadora \\
\hline Escolinha I & Professora irritada \\
\hline Escolinha II & A visita da médica \\
\hline Escolinha III & Desenho ou maquiagem? \\
\hline Escolinha IV & Posso ser professor? \\
\hline Escolinha V & Drogas! \\
\hline Boneca I & Calcinha! \\
\hline Boneca II & Um dia vou ter... \\
\hline Boneca III & Pelos de gato \\
\hline Boneca IV & A injeção \\
\hline Médico I & A consulta médica \\
\hline Médico II & Batendo ao máximo \\
\hline Médico III & Preparando-se para a festa \\
\hline Maquiagem I & Quero brincar disso... \\
\hline Maquiagem II & Tudo de graça! \\
\hline Vendedor & Fazendo salvamento \\
\hline Salvamento & Consertando o caminhão \\
\hline Mecânico & \\
\hline
\end{tabular}

Fonte: Banco de dados da pesquisa (2015).

$\mathrm{O}$ argumento mais frequente foi "casinha" (que apareceu 6 vezes), seguido de “escolinha”(5 vezes), "boneca” (4 vezes), "médico" (3 vezes), "maquiagem”( 2 vezes), e "vendedor", "salvamento" e "mecânico", que apareceram 1 vez cada um. 
Verificou-se que as crianças utilizaram com mais frequência os temas "casinha" "escolinha", que representam o campo relacional nessa faixa etária, o qual se concentra principalmente na família e na escola, na esfera do cuidado com a criança, nos papéis de mãe e de educadora, conforme observado também por Oliveira (2011).

\section{APROFUNDANDO A ANÁLISE}

No segundo nível de análise, estabeleceram-se três núcleos de significação que destacam as situações contraditórias observadas com maior frequência nas brincadeiras: "O adequado. O não adequado"; "O dito. O não dito"; "Eu quero ser... Você não pode ser".

$\mathrm{O}$ núcleo "O adequado. $\mathrm{O}$ não adequado" refletia as permissões sociais levando-se em conta as questões de gênero, constituindo-se a partir das falas infantis referentes a brinquedos adequados para meninos ou para meninas.

Em “O dito. O não dito", as análises objetivaram demonstrar os elementos explícitos e implícitos que emergiram nas situações dos jogos de papéis, para que assim se pudessem apreender os processos de pensamento dos sujeitos.

"Eu quero ser... Você não pode ser" constituiu-se mediante as preferências manifestadas pelos sujeitos por protagonizarem determinado papel e na obtenção ou não de autorização dos demais, permitindo que assim brincassem.

Porém, ainda que cada núcleo de significação apresentasse sua especificidade, eles articulavam-se entre si e suas determinações decorreram dos processos históricos que os constituíram.

No terceiro nível de análise, tomou-se como base cada sujeito em suas relações durante a atividade de jogo de papéis, de acordo com os conteúdos por ele expressos, com o objetivo de identificar como os núcleos de significação estabelecidos manifestaram-se em sua fala. Ao mesmo tempo, analisaram-se alguns aspectos constitutivos de cada sujeito, procurando apreender aspectos sociais que possibilitaram sua constituição.

Ao discutir significado e sentido, buscou-se compreendê-los como constituídos pela relação entre o simbólico e o emocional (Aguiar e Ozella, 2006), entendendo os aspectos cognitivo-simbólicos e emocionais como indissociáveis. Assim, apresenta-se, a seguir, a análise das falas dos sujeitos em algumas situações dos jogos de papéis.

Ao desempenhar os papéis do adulto, a criança apropria-se do sentido social das atividades produtivas humanas e sua conduta é guiada por essa apropriação. Porém, o jogo de papéis contém uma imprevisibilidade e, ao seu final, poder-se-ia supor que nem sempre estarão garantidos à criança o prazer e a satisfação das necessidades que a levaram a brincar. Como pode ser observado no jogo "Que seja de menina...".

Z. (menino, 6 anos) está sozinho dentro da cabana cor-de-rosa brincando com a pipoqueira (brinquedo miniatura do objeto). L.G. (menino, 6 anos) e M. (menino, 6 anos) permanecem do lado de fora, conversando e observando o colega lá dentro. 
Z.: "-Vai pegá o principe pra mim" (dirigindo-se para M.). C. (menina, 6 anos) aproxima-se e Z. a convida: "-Vamo brincá aqui?"; "—Qué que eu ajudo?" (sai da cabana). "-Vô tê que tirá os chinelo" (calçando os chinelos que estavam na saída da cabana). $\mathrm{O}$ convite feito a $\mathrm{C}$. parece ser necessário para que ele possa brincar na cabana cor-de-rosa, já que seus colegas meninos recusam-se a brincar dentro dela. Em poucos segundos, Z. retorna à cabana, descalça os chinelos, adentra e senta-se no chão. Tenta fechar a "portinha" (unir uma parte de tecido a outra com o velcro). Z.: "-Ô Ma tem as chaves..." (fala para M., que está do lado de fora observando o que ele faz).

L.G.: "-Quéque eu ponbo ali pra tu Z.?" (querendo ajudá-lo a unir as partes do velcro para fechar a "porta" da cabana).

Z. apenas sorri para L.G., mas não o autoriza ajudá-lo.

M.: "- Ô Z. deixa eu te fala uma coisa no buraquinho ali?" (M. aproxima-se da cabana, sorri, ajoelha-se próximo a janelinha e cochicha algo pro Z., que está lá dentro. Supõe-se que por ser a cabana cor-de-rosa, avisa para o amigo que um menino não poderia brincar lá dentro. Em seguida afasta-se).

Z. : "- Deixe que seje de menina..." (Z. continua na cabana brincando sozinho com a pipoqueira. Depois de algum tempo sai e a brincadeira termina). (Episódio 224-226 - 1/12/2014)

Momentos antes, ao brincar de casinha com o colega L.G., Z. desmontara a casinha já existente, na qual as meninas estavam brincando, e a remontara embaixo da mesa. Percebe-se que essa ação de montar uma nova casinha em um lugar menos visível era necessária para que assim se autorizassem a brincar com os mesmos brinquedos que as meninas brincavam anteriormente.

O que move uma criança a esse brincar são suas necessidades irrealizáveis, que surgem da percepção dos desafios ou ações que não pode realizar por suas limitações físicas e psicológicas. Portanto essas necessidades não são deflagradas pelo jogo de papéis em si, já existiam antes dele (Prestes, 2010).

A preocupação central da criança não é aprender a usar os objetos humanos ou conseguir realizar as operações genuínas do adulto. O jogo de papéis é a atividade na qual o motivo se encontra em seu próprio processo. Afirmar que o motivo da brincadeira está no processo em si significa dizer que, na verdade, a brincadeira de papeis não está centrada nos objetos que a criança utiliza para representar as diferentes situações, ou mesmo nos personagens que ela encarna. Prova disso é que a criança, ao término da brincadeira, recolhe os brinquedos ou objetos, abandona seus personagens e volta a ser ela mesma.

Apesar de não apresentar objetivamente um desenho ou objeto confeccionado, houve um produto: a ação de brincar. Esse produto é um estado afetivo emocional que permite à criança "assegurar seu êxito mediante as relações que podem estabelecer-se [...] durante a ação ou no final desta" (Elkonin, 2009, p. 220), como no jogo "Vinho ou suco?"

L. H. (menino, 6 anos) brinca com o fogãozinho e tem um copo e uma taça na mão. L.G. (menino, 6 anos) tem um fantoche que aproxima ligeiramente do colega, e este esquiva-se toda vez. 
L.H.: "-Oo... quévinho?? Quévinho?? Ooo... qué vinho?? Ooo... qué vinho pinguço?" (L.G. agora esfrega o fantoche no fogãozinho e não responde a pergunta do colega). "- Ooo... qué vinho?” (L.G. põe várias vezes o fantoche no rosto de L.H., que não gosta. Da última vez que é questionado, esfrega o fantoche no rosto de L.H.). L.H.: "- Ooo... para se não eu vô contá pra profe. Ooo... qué tomá vinho?" (L.G. continua a movimentar o fantoche, agora o esfregando no fogãozinho. L.H. faz de conta que enche a taça e toma. L.G. faz um leve menear com a cabeça negativamente).

Todas as vezes que L.H. perguntou para L.G. se queria vinho, ele não respondeu, apenas movimentou o fantoche. Depois que ameaçou contar à professora, L.H. parou de incomodar o colega com o fantoche.

L.H.: “- Eu tenho uma tatinha pa tu...” (enche a tacinha e dá para o fantoche; L.G. também ajuda). "-Dá pa toma tchuco”. (Mexem com o fantoche, como se fosse para ele engolir o líquido. Os dois fazem de conta que o fantoche bebeu o suco). (Episódio DSC 287 - 8/12/2014)

A criança não representa um adulto com determinada profissão ou ações/operações próprias do mundo dos adultos, como cozinhar/cortar os temperos. Seu foco principal são as relações que os adultos estabelecem entre si ao utilizarem os objetos, as quais se manifestam nas relações que a criança mantém com outras crianças ou com os adultos. Como afirma Elkonin (2009, p. 31): “[...] no jogo protagonizado influi, sobretudo, a esfera da atividade humana, do trabalho e das relações entre as pessoas [...], por conseguinte, o conteúdo fundamental do papel assumido pela criança é, precisamente, a reconstituição desse aspecto da realidade”.

$\mathrm{O}$ que a criança quer reconstituir evidencia-se nos diferentes temas que constituirão o conteúdo revelado nos jogos de papéis. Portanto essa reconstrução do papel de adulto escolhido pela criança está atrelada às suas condições e relações concretas de vida.

A conversão da menina em mãe, e da boneca em filha, dá lugar a que os atos de dar banho, dar de comer e preparar a comida se transformem em responsabilidades da criança. Nessas ações [estão implícitas diversas operações, como preparar a água do banho, esfriar a "papinha” do bebê, etc.], manifesta-se então a atividade da mãe com o filho, seu amor e sua ternura, ou até o contrário [...]. (Elkonin, 2009, p. 404-405)

Nesse sentido, no jogo de papéis, a representação tem como funções, além da interpretação das relações que o papel envolve, a verificação do comportamento do modelo protagonizado pelo intérprete ou demais participantes. A criança tem uma liberdade relativa nesse momento, porque precisa adequar sua conduta ao papel que irá interpretar seguindo as regras que dele decorrem. Assim, a liberdade é uma ilusão. Por isso, Elkonin (2009) considera que o jogo é escola de conduta arbitrada. Como no jogo "Calcinha!"

L.H. (menino, 6 anos) e T. (menino, 6 anos) estão sentados no sofá e brincam com diversos brinquedos pequenos, como roupas e acessórios da boneca Poly. 


\section{T.: "- Onde tá outa boneca???"}

L.H.: "-Não sei..."

Os dois passam a procurar pela boneca Polly, olhando sobre o sofá e nas proximidades. Encontram-na. L.H. veste a bota na boneca e T. segura uma mamadeira. T.: "-Tem bico?"

L.H. continua tentando vestir a bota na boneca, encontrando dificuldade.

T.: "-E a camisa?"

L.H. faz uma cara de descontentamento e procura algo.

T.: "-Aqui tá outra bota..." (entrega para que L.H. vista na boneca). “- Essa saia vai onde... É uma camisa..." (quer avisar que a saia está vestida de modo errado, que é uma camisa e não uma saia).

L.H.: "-Quê?"

T.: "-É uma camisa..."

L.H.: "-Eu num sei..." (procura por alguma coisa e pega uma calcinha de boneca). "-Essa aqui é... CALCINHAAA!!!!.." (larga rapidamente, faz uma cara de nojo mostrando a língua, larga tudo e sai).

Dispersam-se, encerrando a brincadeira. (Episódio 92 - 4/12/2014)

Um aspecto fundamental no jogo de papéis é o fato de propiciar a vivência das normas de conduta que permeiam as relações entre os adultos, possibilitando à criança, ao interpretar, submeter-se às regras que o papel de adulto exige. As relações baseadas nas regras são fonte do desenvolvimento da moral infantil.

Dessa forma, o jogo de papéis promove o conhecimento que a criança tem da realidade social a um nível de compreensão consciente e generalizado. Entretanto, é preciso lembrar que o pleno "[...] desenvolvimento psíquico da brincadeira depende da riqueza do acesso ao conhecimento sobre o mundo que a criança tem (ou não) [...] [depende] de suas condiçôes de vida e de educação" (Pasqualini, 2013, p. 90).

A criação da situação imaginária, a definição das regras específicas e a capacidade da criança de controlar seu próprio comportamento para alcançar determinado fim nas situações de jogos de papéis têm uma importância fundamental no desenvolvimento cognitivo infantil, por produzir uma zona de desenvolvimento iminente (ZDI). ${ }^{3}$ Ela passa a comportar-se de forma mais evoluída que nas atividades da vida real e, assim, aprende a separar objeto e significado, o que contribui para o desenvolvimento infantil, uma vez que ao "[...] realizar essa ação [que ainda não domina na realidade] resolve a contradição entre a necessidade de agir, por um lado, e a impossibilidade de executar as operações exigidas pela ação, de outro" (Facci, 2004, p. 69).

Essas considerações conduzem à compreensão de que o que determina o aceite ou a recusa para brincar são os conhecimentos e as ideias, o significado e o sentido que as crianças trazem acerca do conteúdo fundamental do jogo de papéis que está sendo protagonizado. Todos esses elementos constituem as normas de conduta que permeiam as relações entre os adultos, como pode ser observado no

3 A zona de desenvolvimento iminente (ZDI) corresponde à zona de desenvolvimento proximal (ZDP), expressão utilizada anteriormente ao trabalho de tradução de Zoia Prestes (2010). 
jogo "Posso ser professor", referente ao qual se apresenta uma breve descrição e alguns excertos a seguir.

Nesse jogo as crianças retratam o cotidiano da sala de aula e as atividades realizadas por alunos e professora, entre elas o ensino e a escrita das letras. L.H., apesar de não estar diretamente envolvido na brincadeira de escolinha, realiza uma tentativa para ser aceito e experiencia o conflito entre querer e não poder ser professor, em razão da colega não aceitá-lo.

L.H. adentra a sala de aula e senta-se próximo a colega A.M. (menina, 5 anos), que protagoniza o papel da professora e coordena o jogo.

A.M.: "-Vê se não mexe nas coisas... Qué se também professor?"

L.H.: "-Sim".

A.M.: “- Tá... então tu tem que buscá umas coisa primeiro..." (ela deixa L.H. esperando, sem falar o que ele deveria buscar. Não lhe dá atenção).

$[\ldots]$

L.H. intervém porque já está impaciente esperando A.M. dizer o que ele deveria buscar.

L.H.: "- Buscá algumas coisa?..."

Ela continua não respondendo para L.H. Dá atenção e conversa com os demais participantes do jogo.

[...]

L.H. sai para buscar algumas coisas, quando retorna entrega à A.M. alguns fantoches em EVA.

\section{L.H.: "-Viu... busquei fantoche".}

Ela pega na mão, mas logo os deposita no chão, sem dar importância. L.H. senta-se novamente e continua esperando poder participar da brincadeira.

Revelam-se e são mobilizadas, no jogo, as funções psíquicas eminentemente humanas que possibilitam à criança interagir no mundo. A percepção e a atenção aos objetos que a cercam, a memória de situações vivenciadas, emoções, volição - ao querer desempenhar determinado papel, a conduta guiada pelas exigências que este pressupõe, seu pensamento orientando suas ações, sua linguagem possibilitando a interação. Porém, como afirma Martins (2013), essas funções manifestam-se e entram em ação em conjunto, uma relacionando-se com a outra, constantemente, pois sem a participação dessas funções, manifestas e internalizadas, não pode haver brincadeira de papéis.

Observa-se que a protagonização de determinado papel por um integrante do grupo precisa ser aceita pelos demais. Quais motivos levam a criança a pensar que seu colega não será capaz de desempenhar o mesmo papel que ela desempenha, no caso ora relatado, de professora? Por que A.M. julga L.H. incapaz de ser professor e por isso tenta enganá-lo, solicitando que busque "umas coisas primeiro", as quais ela não explicita? Parece que apenas quer mantê-lo iludido e sob seu domínio. Mesmo quando o menino toma a iniciativa de providenciar alguns objetos, A.M. os ignora e continua a não autorizá-lo a ser professor, talvez para não abdicar desse papel.

Pela primeira vez, L.H. demonstra interesse em representar o papel de professor, disputado entre os colegas e já protagonizado por aqueles menos inibidos 
e com maior desenvoltura para interagir. Percebe-se que L.H. busca ampliar suas capacidades de falar e portar-se ao procurar assumir o papel docente. $O$ papel de professor é uma situação desafiadora para ele, impulsiona-o à autonomia e à tomada de decisão, demonstradas ao sair da sala e buscar fantoches em cumprimento à condição enunciada por A.M., mas não revelada, usada apenas como pretexto para mantê-lo por perto e dependente do que ela deveria designar. L.H. sujeita-se à condição imposta por A.M. porque valoriza o papel de professor desempenhado pelo adulto e demonstra sentir-se alegre e empoderado a fazê-lo.

[...] isso significa que a criança vê o adulto, sobretudo, pelo lado de suas funções. Quer atuar como o adulto, [...] sob a impressão desse desejo muito geral, primeiro mediante as sugestões do adulto (o educador ou os pais), começa atuando como se também ela o fosse. Essa sensação é tão grande, que basta uma pequena alusão para que a criança se converta alegremente, claro que no aspecto puramente emotivo, em adulto. É pela força dessa sensação que se explica a facilidade com que as crianças assumem os papéis dos adultos. (Elkonin, 2009, p. 404)

Mesmo antes de ter autorização para ser professor na brincadeira, L.H. passa a atuar como um professor, pois, ao retornar com "uma coisa", o faz com um fantoche, material pedagógico muito utilizado durante as aulas na educação infantil para contação de histórias.

As manifestações infantis presentes no jogo descrito revelam o aspecto de conduta arbitrada, isto é, o desempenho de ações coerentes com o papel assumido. Remetem, ainda, às questões de moralidade na ação, ou seja, começa a ocorrer uma incipiente avaliação da fidedignidade das ações em relação à similitude com o modelo, em virtude da qual essas ações serão ou não permitidas. Porém, ainda que essa verificação seja muito débil, “[...] o valor do jogo consiste em que essa função nasce aí. É precisamente por isso que se pode considerar que o jogo é escola de conduta arbitrada" (Elkonin, 2009, p. 420).

Essas considerações revelam a ideia de que as crianças durante o jogo de papéis aprendem a controlar umas às outras, a exercer algum tipo de poder, a discriminar e, assim, formam-se os preconceitos acerca do autorizado e não autorizado, do certo e do errado, do bom e do mau, do belo e do feio, entre outros.

A brincadeira de papéis [...] possibilita à criança superar o nível de consciência limitado ao imediatamente presente, isto é, permite-lhe a atividade abstrata (teórica). Com isso, o alvo de suas ações vai deixando de ser o conteúdo do ato específico, deslocando-se para o processo que articula várias ações e vários objetos, presentes ou simbolizados. Consequentemente, a amplitude e complexidade do mundo humano são percebidas pela criança, desafiando-a para seu domínio e culminando numa total reestruturação de sua consciência. (Martins, 2006, p. 42-43)

O jogo em análise — "Posso ser professor?” — sugere uma relação de poder entre quem autoriza ou desautoriza os papéis de adultos a serem protagonizados, portanto tem o domínio tanto das relações sociais que esses adultos desenvolvem quanto das relações entre as crianças participantes no transcorrer do jogo. Nesse caso, 
a menina A.M. demonstra ter esse domínio e o menino L.H. motiva-se a alcançá-lo quando se desafia a ser o professor.

O poder humano refere-se às formas de ser, agir, pensar e sentir como produtos da própria atividade da vida sociocultural, desenvolvendo-se como possibilidade de ação e como atividade orientadora no meio, com a finalidade de satisfazer às necessidades do sujeito. Desse modo, dominar-se e dominar os conhecimentos do mundo no qual se vive é expressão de poder (Marino Filho, 2010).

Quando a criança tem a necessidade de protagonizar determinado papel no jogo, surge para ela uma possibilidade de atividade especial, promotora de desenvolvimento. Assim, o jogo de papéis oportuniza o surgimento de novas necessidades, as quais levam o sujeito a querer protagonizar novos papéis, experienciando diferentes formas de poder. Destarte, a criança passa a vivenciar o sentimento de ser capaz de exercer maior influência na brincadeira, sentindo o poder social desse novo papel. Esse poder não é algo natural, e sim algo a ser produzido no indivíduo por meio das relações sociais.

Ao não abandonar o papel de professora, A.M. não quer abrir mão do poder que esse papel lhe dá. Quando L.H. lhe entregou o fantoche,A.M. o recebeu com um lacônico “Tá!", não interagiu com L.H., o que poderia revelar sua limitação quanto ao papel mediador que a linguagem verbal teria nas negociações. Contudo, também L.H. revelou a mesma limitação ao não reagir, ao não se expressar verbalmente.

Durante os episódios, observou-se que, no jogo de papéis de escolinha, o papel de professor(a) não foi imitado por todos os alunos, mas por aqueles que demonstravam ter o domínio das ações que o papel exigia e a simpatia dos demais participantes da brincadeira. "Não basta adquirir um determinado poder, é preciso aprender a usá-lo em diferentes situações e ter condições para dominar as esferas de sua realização" (Marino Filho, 2010, p. 267).

Assim, a organização do procedimento de pesquisa possibilitou a dilatação do espaço e do tempo para a brincadeira de papéis, ao passar da primeira para a segunda fase de coleta de dados. Quando no planejamento pedagógico ampliou-se esse espaço, ampliaram-se as possibilidades de negociação e de empoderamento pessoal, possibilitando melhores condições para a interação mediadora entre as crianças.

No jogo emergiram diferentes processos psíquicos: aspectos da vivência infantil que chamaram a atenção da criança, que os percebeu e os reteve na memória, expressando-os como pensamentos pela linguagem, uma vez que "a função pensamento [atua] como um 'reagente' (por analogia aos processos químicos!) de todas as funções psíquicas" (Martins, Abrantes e Facci, 2016, p. 24). Nesse sentido, constatou-se uma evolução na linguagem verbal das crianças ao longo dos diferentes jogos de papéis observados, o que permite afirmar que houve um desenvolvimento do pensamento.

A última análise reveste-se de uma singularidade pelo conteúdo do jogo - drogas - utilizado pelos meninos Z. e G.B., que brincavam de escolinha e, em dado momento, iniciaram um diálogo sobre "maconha".

Da transcrição do jogo, extraíram-se algumas falas do menino Z.: "[maconha] é "dogas", "[não faz] nada”, "maconha é cigarro", "doga é dinheiro", "eles [os bandidos] 'robam". O que foi dito pelo menino Z. revela uma realidade à qual, muito precocemente, as crianças estão expostas e que, no entanto, contrasta com o "mundo protegido" que a escola busca proporcionar às crianças. Tais fa- 
las referem-se aos diferentes sentidos que $Z$. atribui às drogas advindos de seu contexto social.

O menino não disse simplesmente palavras, empregou-as manifestando sua consciência e o sentido pessoal e moral que ele lhes atribuía. Percebe-se que os significados sociais atribuídos às palavras "maconha", "droga" e "cigarro" foram parcialmente apreendidos por Z., com o sentido de que as drogas não fazem nada, com elas apenas são produzidos cigarros e elas são fonte de dinheiro. Os traços de caráter formam-se e se desenvolvem na relação do indivíduo com o meio, isto é, unicamente na coletividade, que institui os modelos de reação que se vão firmando perante situações idênticas ou semelhantes. Nas relações sociais estabelecidas, o homem assimila modelos de reação orientados por normas, regras, costumes, exigências morais, entre outros, próprias do grupo ao qual pertence. Portanto a vivência social institui não só os modelos de reações às circunstâncias, mas também os parâmetros para a autoanálise, fornecendo os pontos de orientação pelos quais as pessoas conduzem seus comportamentos (Martins, 2006, p. 37).

\section{EXTRAPOLANDO OS MUROS DA ESCOLA}

A discussão sobre drogas entre os dois meninos lança pistas sobre o processo de inserção no universo sociocultural da comunidade onde vivem. Revela indícios sobre exigências morais e formas de reação às circunstâncias em que essas crianças se inserem. Destarte, aponta para a importância do papel social da escola, que, embora se constitua como parte dessa trama social, apresenta-se como um lugar em que, para além de seu compromisso de transmissão da cultura historicamente construída pelos homens, as crianças, principalmente as das classes menos favorecidas, podem ser acolhidas e protegidas do assédio de aliciadores, traficantes, enfim dos graves problemas sociais atuais.

Ressalta-se, portanto, a importância de que a sociedade contemporânea preocupe-se em buscar maneiras de enfrentamento dos efeitos que os problemas econômicos, políticos e sociais têm no desenvolvimento infantil, salientando o jogo de papéis como um dos modos de a criança elaborar esses efeitos. Nessa perspectiva, destaca-se a necessidade de políticas públicas que possibilitem acolhê-la em período integral no espaço formativo escolar e ouvi-la, propiciando condições mais favoráveis para protegê-la e orientá-la.

Assim como a aprendizagem orienta e estimula processos internos de desenvolvimento, o jogo de papéis também propicia o desenvolvimento por provocar novas necessidades que impulsionam mudanças evolutivas.

[...] a criança sempre se comporta muito além do comportamento habitual para sua idade. Ela age como se fosse mais velha, maior, mais forte, mais capaz do que é na realidade. Ela age ou tenta agir como um adulto em relação aos objetos e conceitos do mundo adulto, do universo humano. Assim, tendo como referência o comportamento do adulto, [...] [o jogo de papéis] contém, de forma condensada, todas as tendências do desenvolvimento posterior da criança. (Rossler, 2006, p. 60-61) 
Vivenciar situações imaginárias oportuniza um salto no desenvolvimento infantil, além de possibilitar à criança o sentido de pertença social, uma das necessidades mais fortes no ser humano. A criança passa a comportar-se com maior maturidade, procurando resolver a nova situação que protagoniza. Ela precisa solucionar a contradição gerada pelo que quer e pelo que não pode ainda realizar, por isso cria um mundo imaginário no qual atende as suas necessidades. Surge assim uma nova relação entre a situação pensada e a situação real, entre o campo semântico e o campo visual, impulsionando o primeiro deles.

Enfim, o jogo de papéis oportuniza "[...] uma situação de transição entre a ação da criança com objetos concretos e suas ações com significados” (Oliveira, 2011, p. 69). Pela mediação social, amplia-se o desenvolvimento da linguagem e o sistema de signos utilizado pela criança. Ao utilizar os jogos de papéis, a criança toma posse do mundo concreto dos objetos humanos, relaciona-se ativamente com os objetos utilizados pelos adultos, desenvolve a consciência acerca do mundo objetivo, bem como vai estabelecendo limite entre o que já domina e o que ainda não pode dominar naquilo que diz respeito a operações e ações.

O jogo de papéis amplia o repertório dos envolvidos, pois favorece a interação entre os colegas, possibilitando novas apropriações. A relação é de reciprocidade, na escola novos enredos ficam conhecidos, as ações tornam-se mais complexas à medida que os papéis vão sendo diversificados. É a vida que pulsa fora da escola, manifestando-se dentro dela. "Como se enriquece o conteúdo do jogo? A fonte fundamental [...] são as ideias que as crianças têm da realidade circundante; e se não as têm, não se pode levar o jogo a cabo" (Elkonin, 2009, p. 302).

\section{CONSIDERAÇÕES FINAIS}

Esta pesquisa pautou-se na concepção de que as funções psicológicas superiores, tais como sensação, percepção, atenção, memória, linguagem, pensamento, imaginação ou afeto, são funções do gênero humano e atuam em conjunto, desenvolvendo-se de forma articulada. No entanto, a complexificação desse processo de desenvolvimento depende da vivência das atividades práticas externas, que engendram oportunidades de assimilação dos sistemas de signos, aos quais o indivíduo está exposto.

Nesse sentido, entre as atividades cotidianas produzidas pelas crianças de 5-6 anos, o jogo de papéis constitui-se em atividade principal para o processo de humanização e de apropriação cultural nessa faixa etária. Essas brincadeiras contribuem para que os pequenos constituam a personalidade, aprendam a agir diante das coisas e das pessoas, uma vez que as ações que realizam em suas protagonizações tanto reproduzem relações vividas quanto estruturam processos internos, orientando a apropriação de outras ações práticas, mais autônomas.

Verificou-se que o movimento e a vivência das relações propiciadas pelos jogos de papéis permitem a materialização do desenvolvimento dos processos funcionais, favorecem a imaginação e o uso de signos e estimulam novas necessidades que impulsionam mudanças evolutivas. Ao exercer ação sobre os instrumentos, a criança reproduz as relações sociais que a constitui, ou seja, ao protagonizar papéis e brincar com outras crianças, adultos e brinquedos disponíveis em seu entorno, apropria-se do sentido social das atividades produtivas humanas, as quais, por 
tratar-se de funções relacionais, dependem das condições sociais em que o sujeito se insere e não podem envolver um indivíduo isoladamente.

A análise dos jogos de papéis revelou que as crianças utilizaram diferentes recursos anteriormente apropriados em suas vivências. Assim, ampliaram suas percepções sobre o mundo, sobre si e sobre os outros; organizaram seus pensamentos; lidaram com seus afetos; promoveram suas capacidades de imaginar e criar, entre outras. Enfim, aprimoraram suas funções psicológicas superiores e construíram conhecimentos e sentidos pessoais sobre si e sobre o mundo.

Ao desejar viver o que os adultos vivem, as crianças colocaram-se imaginariamente na zona de desenvolvimento iminente, indo além das suas possibilidades reais no momento, o que fez com que elas "funcionassem" melhor, isto é, fossem mais ativas à medida que novas interações ocorriam, possibilitando-lhes um desenvolvimento mental prospectivo.

No jogo de papéis, a criança reconhece suas capacidades e potencialidades, expõe suas opiniões acerca da sociedade em que vive, demonstra seus sentimentos e julgamentos éticos e morais, comunica-se, revela sua consciência na busca de humanizar-se. "E é justamente assim que as funções se desenvolvem: quando são demandadas pela atividade, quando a atividade exige que entrem em funcionamento e avancem em complexidade" (Pasqualini, 2013, p. 89).

Nesse processo, a educação para essa transformação humanizadora tem o papel de agregar os elementos culturais, objetivando produzir no homem uma natureza específica relacionada aos conhecimentos históricos eleitos. Trata-se de "produzir o particular a partir da totalidade". Desse modo, torna-se objeto da educação a “[...] descoberta das formas mais adequadas para atingir esse objetivo" (Saviani, 2013, p. 13).

Nessa perspectiva, mediante a constatação do potencial educativo e de desenvolvimento das funções psicológicas superiores por meio da vivência dos jogos de papéis na educação infantil, esta pesquisa propõe a inserção de espaços na rotina de sala de aula promovendo a brincadeira espontânea infantil, na qual os jogos de papéis possam emergir. Destaca-se, assim, não só a importância do professor como mediador, mas a necessidade de compreender o desenvolvimento humano como objeto central para a organização dos processos educativos que realmente promovam e efetivem o desenvolvimento da criança (Szymanski; Colussi, 2018, p. 49). Trata-se da compreensão de que tais jogos promovem aprendizagem a serviço do desenvolvimento do pensamento, da atenção voluntária, da memória lógica, da linguagem, da imaginação, dos sentimentos, entre outras funções psíquicas, e ainda possibilitam à escola um olhar para as crianças pelo que elas são, pensam e sentem.

Um aspecto importante a ser ressaltado é que o trabalho do professor de educação infantil voltado ao desenvolvimento psíquico da criança, tendo como atividade-guia o jogo de papéis, é encaminhar-se para o futuro, para o "vir a ser" do psiquismo infantil. Por isso, ao abrir o espaço e o tempo necessário para que os jogos de papéis surjam, o professor promove as premissas básicas para o novo período do desenvolvimento psíquico, no qual a atividade de estudo será a atividade-guia. Enfim, brincar de faz de conta não é fazer de conta que se brinca.

Como se pode verificar nos excertos analisados, embora as brincadeiras de papéis sejam improvisadas, não se constituem em atividade espontânea. Fazem parte 
do repertório social, trazem consigo a história das crianças e são base para o aprimoramento dos atributos e propriedades humanas, pois "a história pode ser recuperada como processo pela sua objetivação" (Marino Filho, 2007, p. 155). Observou-se que os fragmentos da história apresentados extrapolam a sala de aula e induzem a outros questionamentos quanto às implicações que se estabelecem entre o contexto em que a criança vive e seu desenvolvimento psíquico.

A criança contemporânea traz valores, informações e experiências cuja vivência prematura contribui para naturalizar questões que são histórica e socialmente construídas, confrontam a imagem de criança inocente proposta pelo ideário moderno. Quando se compreende o processo de constituição da subjetividade, compreende-se por que e como questões sociais, políticas e econômicas, que vêm assumindo proporções a cada dia mais graves, manifestam-se na escola.

Sendo socialmente construídas, essas questões não podem ser naturalizadas, isto é, compreendidas como se estivessem permeando a sociedade em um processo natural.É “[...] preciso perquirir o tecido histórico-social a partir do qual se explicitam uma determinada consciência e certas categorias ou necessidades". Essa indagação revela que a lógica do lucro privado ao ampliar a exclusão vem agravando cada vez mais os problemas sociais, e essa relação é produzida historicamente (Frigotto, 1994, p.36), o que nos obriga a refletir e assumir, como sujeitos históricos, esses problemas.

Portanto, ao mesmo tempo em que avança o conhecimento teórico sobre a infância, os problemas decorrentes das discrepâncias sociais invadem a criança contemporânea e consequentemente a escola, acarretando imensos desafios a pais e educadores. Trazer para a escola, simbolicamente, por meio dos jogos de papéis, os problemas e as situações vivenciadas pelas crianças pode permitir-lhes novos modos de olhar para essas questões, de forma que possa superar a banalização do cotidiano.

$\mathrm{E}$, se a realidade social é produzida historicamente, cabe a nós, pais e educadores, sermos protagonistas dessa história e lutarmos por políticas públicas que proporcionem às crianças, especialmente as das classes populares, a possibilidade de ampliar sua estadia na escola para tempo integral, alargando as alternativas para protegê-las, ainda que parcialmente, da vivência precoce das situações de violência que se manifestam em seu contexto social mais amplo.

\section{REFERÊNCIAS}

AGUIAR, W. M. J.; OZELLA, S. Núcleos de significação como instrumento para a apreensão da constituição dos sentidos. Psicologia: Ciência e Profissão, Brasília, v. 26, n. 2, p. 222-245, jun. 2006. https://doi.org/10.1590/S1414-98932006000200006

AGUIAR, W. M. J. A pesquisa em psicologia sócio-histórica: contribuições para o debate metodológico. In: BOCK, A. M. B.; GONÇALVES, M. G. M.; FURTADO, O. (org.). Psicologia sócio-histórica: uma perspectiva crítica em psicologia. São Paulo: Cortez, 2001.p. 129-140.

COLUSSI, L. G. Contribuições dos jogos de papéis para o desenvolvimento das funções psicológicas superiores. 2016.153 f. Dissertação (Mestrado) — Universidade Estadual do Oeste do Paraná, Cascavel, 2016. Disponível em: http://tede.unioeste.br/ handle/tede/3325. Acesso em: 25 mar. 2020. 
COUTO, N. S. O papel regulador da linguagem no jogo de papéis: alunos na escola, crianças na vida. 2013.292 f. Tese (Mestrado em Educação) - Universidade Estadual Paulista "Julio de Mesquita Filho", Marília. Disponível em: https://repositorio.unesp. $\mathrm{br} /$ bitstream/handle/11449/106627/couto_ns_dr_mar.pdf?sequence=1\&isAllowed=y. Acesso em: 13 mar. 2020.

ELKONIN, D. B. Sobre el problema de la periodizacion del desarrollo psíquico em la infancia. In: DAVIDOV, V.; SHUARE, M. La psicologia evolutiva e pedagogica en la URSS. Moscou: Editorial Progresso, 1987. p. 125-142.

ELKONIN, D. B. Psicologia do jogo. 2. ed. São Paulo: Martins Fontes, 2009.

FACCI, M. G. D. A periodização do desenvolvimento psicológico individual na perspectiva de Leontiev, Elkonin e Vigostki. Cadernos CEDES, Campinas, v. 24, n. 62, p. 64-81, jan./abr. 2004. Disponível em: http://www.scielo.br/scielo.php?script=sci_ abstract\&pid=S0101-32622004000100005\&lng=en\&nrm=iso\&tlng=pt. Acesso em: 26 mar. 2020. https://doi.org/10.1590/S0101-32622004000100005

FRIGOTTO, G. Educação e formação humana: ajuste neoconservador e alternativa democrática. In: GENTILI, P.; SILVA, T. T. (org.). Neoliberalismo, qualidade total e educação. Petrópolis: Vozes, 1994. p. 31-92.

LAZARETTI, L. M. Daniil Borisovich Elkonin: um estudo das ideias de um ilustre (des) conhecido no Brasil. 2008.252 f. Dissertação (Mestrado) — Faculdade de Ciências e Letras de Assis, Universidade Estadual Paulista "Julio de Mesquita Filho", Assis, 2008. Disponível em: https://repositorio.unesp.br/bitstream/handle/11449/97544/ lazaretti_lm_me_assis.pdf?sequence=1. Acesso em: 12 mar. 2020 .

LEONTIEV, A. O desenvolvimento do psiquismo. Lisboa: Livros Horizonte, 1978. LEONTIEV, A. N. Os princípios psicológicos da brincadeira pré-escolar. In: VIGOTSKII, L. S.; LURIA, A. R.; LEONTIEV, A. N. Linguagem, desenvolvimento e aprendizagem. São Paulo: Ícone, 2016. p. 119-142.

LURIA, A. R. Curso de psicologia geral: introdução evolucionista à psicologia. 2. ed. Rio de Janeiro: Civilização Brasileira, 1991.v. I.

MARINO FILHO, A. Relações de poder e dominação no processo educativo. 2007. 265 f. Dissertação (Mestrado em Educação) - Faculdade de Filosofia e Ciências, Universidade Estadual Paulista "Júlio de Mesquita Filho", Marília, 2007. Disponível em: http://hdl.handle.net/11449/91270. Acesso em: 6 fev. 2015.

MARINO FILHO, A. A necessidade da educação do poder e do domínio para as relações sociais e políticas. Psicologia Política, São Paulo, v. 10, n. 20, p. 259-274, jul./dez. 2010.

MARTINS, L. G. O desenvolvimento do psiquismo e a educação escolar: contribuições à luz da psicologia histórico-cultural e da pedagogia histórico-crítica. Campinas: Autores Associados, 2013.

MARTINS, L. M. A brincadeira de papéis sociais e a formação da personalidade. In: ARCE, A.; DUARTE, N. (org.). Brincadeira de papéis sociais na educação infantil: as contribuições de Vigotski, Leontiev e Elkonin. São Paulo: Xamã, 2006. p. 27-50. 
Martins, L. M.; Abrantes, A. A.; FACCI, M. G. D. Periodização histórico-cultural do desenvolvimento psíquico: do nascimento à velhice. Campinas: Autores Associados, 2016.

OLIVEIRA, Z. M. R. Jogo de papéis: um olhar para as brincadeiras infantis. São Paulo: Cortez, 2011.

PASQUALINI, J. C. Periodização do desenvolvimento psíquico à luz da escola de Vigotski: a teoria histórico-cultural do desenvolvimento infantil e suas implicações pedagógicas. In: MARSIGLIA, A.C. G. (org.). Infância e pedagogia histórico-crítica. Campinas: Autores Associados, 2013. p. 71-97.

PRESTES, Z. R. Quando não é quase a mesma coisa: uma análise de traduções de Lev Semionovitch Vigotski no Brasil: repercussões no campo educacional. 2010.295 f. Tese (Doutorado em Educação) - Faculdade de Educação, Universidade de Brasília, Brasília, 2010.

ROSSLER, J. H. O papel das brincadeiras de papéis sociais no desenvolvimento do psiquismo humano. In: ARCE, A.; DUARTE, N. (orgs.). Brincadeiras de papéis sociais na educação infantil: as contribuições de Vigotski, Leontiev e Elkonin. São Paulo: Xamã, 2006. p. 51-64.

SAVIANI, D. Pedagogia histórico-crítica: primeiras aproximações. 11. ed. rev. Campinas: Autores Associados, 2013.

SZYMANSKI, M. L. S.; COLUSSI, L. A presença dos jogos de papéis na Educação Infantil. Revista de Educação Pública, Cuiabá, v. 28, n. 67, p. 41-61, jan./abr. 2019.

VYGOTSKY, L. S. Obras escogidas. Tradução de Lydia Kuper. Madrid: Visor, 1995. t. III.

VYGOTSKY, L. S. Obras escogidas. Tradução de Lydia Kuper. Madrid: Machado Libros, 2012.t. IV.

\section{SOBRE AS AUTORAS}

Maria Lidia Sica Szymanski é doutora em psicologia escolar e do desenvolvimento humano pela Universidade de São Paulo (USP). Professora da Universidade Estadual do Oeste do Paraná (UNIOESTE).

E-mail:szymanski_@hotmail.com

Lisiane Gruhn Colussi é mestre em educação pela Universidade Estadual do Oeste do Paraná (UNIOESTE). Professora da rede pública de ensino do estado do Paraná.

E-mail: lisianegcolussi@gmail.com 